\title{
Screw Conveyors Power and Throughput Analysis during Horizontal Handling of Paddy Grains
}

\author{
Hemad Zareiforoush (Corresponding author) \\ Department of Mechanical Engineering of Agricultural Machinery, Faculty of Agriculture \\ University of Urmia, P.O. Box 165, Urmia 57135, Iran
}

Tel: 98-131-669-0052Ｅ-mail: hemad.zareiforoush@yahoo.com

Mohammad Hasan Komarizadeh

Department of Mechanical Engineering of Agricultural Machinery, Faculty of Agriculture

University of Urmia, P.O. Box 165, Urmia 57135, Iran

Tel: 98-441-297-2348 E-mail: m.h.komarizade@gmail.com

Mohammad Reza Alizadeh

Rice Research Institute of Iran (RRII), P.O. Box 1658, Rasht 41235, Iran

Tel: 98-131-669-0052 Email: alizadeh_mohammadreza@yahoo.com

\author{
Mahdi Masoomi \\ Department of Mechanical Engineering of Agricultural Machinery, Faculty of Agriculture \\ University of Urmia, P.O. Box 165, Urmia 57135, Iran \\ Tel: 98-131-669-0052Ｅ-mail: mahdimasoomi@gmail.com
}

The research is financed by the Faculty of Agricultural Engineering, University of Urmia, Urmia, Iran and Rice Research Institute of Iran (RRII).

\begin{abstract}
The tests reported in this research were conducted to determine the effects of those parameters believed to have the greatest influence upon horizontal screw conveyors throughput capacity and power requirement when handling paddy grains. Two screw conveyors with diameters of 20 and $25 \mathrm{~cm}$ were evaluated at four screw clearances $(6,9$, 12 and $15 \mathrm{~mm})$ and five screw rotational speeds $(200,300,400,500$ and $600 \mathrm{rpm})$. The results revealed that for both the conveyors tested, with increasing the screw rotational speed, the conveyor capacity increased and reached to a maximum point and after the point, the volumetric capacity decreased. Increasing the screw speed caused the volumetric efficiency and power requirements of the conveyors to be decreased and increased, respectively. The throughput capacity and power requirement of the conveyors increased $(P<0.01)$ with increasing the auger dimensions. As the screw clearance increased, the throughput capacity and power requirement of the conveyors decreased $(P<0.01)$.
\end{abstract}

Keywords: Screw conveyor, Power, Capacity, Conveying, Screw clearance, Rotational speed

\section{Introduction}

Screw conveyors are popular devices for conveying farm products. Thousands of portable units have been used to move or elevate grains into and out of storage bins. As one aspect of increased farmstead mechanization, many auger conveyors are being installed as integral parts of continuous-flow systems. They are very effective conveying devices for free flowing or relatively free flowing bulk solids, giving good throughput control and providing environmentally clean solutions to process handling problems because of their simple structure, high efficiency, low cost and maintenance requirement. Screw conveyors vary in size from 75 to $400 \mathrm{~mm}$ in diameter and from less than $1 \mathrm{~m}$ to more than $30 \mathrm{~m}$ in length (Athanasiov et. al., 2006). They are available as independent mobile items or as a part of other grain handling systems such as harvesters, field bins, dryers, storage or silo 
systems, and feed mixing and distribution systems. The performance of a screw conveyor, as characterized by its capacity, volumetric efficiency, and power requirements, is affected by the conveyor geometry and size, the properties of the material being conveyed, and the conveyor operating parameters such as the screw rotational speed and conveying angle (Srivastava et al., 2006).

For economical installation and dependable performance, the capacity and power requirement of each component of a system must be accurately predicted. In recent years, evaluation of screw augers performance has been carried out by researchers. There are some papers in this area:

Chang and Steele, (1997) investigated the performance characteristics of the inlet section of a screw conveyor for two corn lots. Burr et al., (1998) designed and evaluated an auger with linear tapered inside diameter having a minimum flighting height for uniform unloading particulate materials from rectangular cross-section containers. Nicolai et al., (2004) determined the capacity, volumetric efficiency, and power requirements for a $20 \mathrm{~cm}$ and a 25 $\mathrm{cm}$ diameter conveyor in transporting corn operating in a speed range of 250 to $1100 \mathrm{rpm}$ and inclination angles of 13, 20, and 30 degrees. Moysey and Thompson (2005) developed a new 3-D model for solids conveying in a single screw extruder using DEM. The model has been shown to be suitable tool for studying the local phenomenon of solids flow within the screw channel. Maleki et al., (2006) evaluated the seed distribution uniformity of a multi-flight auger as a grain drill metering device. Dai and Grace (2008) developed a theoretical model for the torque requirement of a screw feeder by considering the bulk solid mechanics of a material element within a pocket. Asghari et al., (2008) studied the effect of auger speed and air flow on discharge rate of bagasse.

However, reviewing of the literature showed that there is no result concerning the screw conveyors performance evaluation in handling of paddy (Oriza Sativa L.) grains. Nowadays, screw conveyors are widely being used in paddy harvesting and post-harvesting equipments. For example, in a rice combine, augers are used to move cut crop on the platform to the feeder housing, clean grain from the bottom of the cleaning shoe to the grain tank, and to unload the grain tank onto a wagon or a truck. Screw conveyors are also used at grain elevators and farmsteads to load grain storage bins and on feedlots for feed distribution. Moreover, the maximum capacity and power requirements of a screw conveyors vary as functions of many parameters defined as screw conveyor performance characteristics, including screw rotational speed, auger diameter, angle of inclination, design of intake section, clearance between auger and housing, pitch of auger flighting, and type of material being conveyed (Nicolai et al., 2006). Hence, the objective of this research was to analysis of throughput and power requirements of screw conveyors, in transporting the paddy grains. The tests reported here were conducted to determine the effects of those parameters believed to have the greatest influence upon horizontal screw conveyor capacities and power requirements when handling agricultural grains. The three variables tested were auger diameter, screw clearance and screw rotational speed. Considering the widely use of this type of conveying equipments in agricultural applications, the results offered in this study can be useful in proper design and adjusting the screw conveyors performance characteristics according to the type of application and specifications of the materials being conveyed.

\section{Materials and methods}

\subsection{Samples preparation}

The paddy grains used in the current research were obtained from the Rice Research Institute of Iran (RRII), Rasht, Iran. The variety evaluated in this research, Hashemi, is one of the local varieties of rough rice in the northern provinces of Iran, which is characterized by slender kernels and long awns (Alizadeh et al., 2006). Before starting the experiments, the samples were cleaned to remove all foreign materials such as grit, chaff, straw, and stems. The initial moisture content of the samples was determined by oven drying method at $130 \pm 1{ }^{\circ} \mathrm{C}$ for $24 \mathrm{~h}$ (Pan et al., 2008). Consequently, it was revealed that the initial moisture content of the samples was $11.2 \%$ (w.b.). The bulk density of the paddy grains at this level of moisture content was $390 \mathrm{~kg} \mathrm{~m}^{-3}$ (Zareiforoush et al., 2009).

\subsection{Experimental procedure}

The performance characteristics of screw conveyors were investigated with respect to auger diameter, screw clearance and screw rotational speed. Screw clearance is defined as the diametrical distance between the rotating flight and its stationary housing wall (Srivastava et al., 2006). Two conveyors with different dimensions were evaluated in the current research for throughput and power requirements. The $20 \mathrm{~cm}(8 \mathrm{in})$ conveyor was made with $17.5 \mathrm{~cm}$ ( 7 in) diameter for screw and $4.5 \mathrm{~cm}$ (1.8 in) diameter for screw shaft; and the $25 \mathrm{~cm}$ (10 in) conveyor had a $22.5 \mathrm{~cm}$ (9 in) screw diameter and $6 \mathrm{~cm}(2.4 \mathrm{in})$ shaft diameter. Both the evaluated conveyors were $150 \mathrm{~cm}$ long with standard screw pitch (pitch is defined as the distance between adjacent screw flights). 
In order to investigate the effect of screw clearance on the performance specifications of the screw conveyors, four clearances, namely, 6, 9, 12 and $15 \mathrm{~mm}$ were considered. For achieving to these levels, an apparatus was specifically made for this research with the capability of adjusting the screw clearance between the rotating flight and its stationary housing wall (Fig. 1). The screw clearance was adjustable by installing the conveyors housing on a lifting mechanism. The inlet section of the conveyors was $32 \mathrm{~cm}$ long. The conveyors were driven by a 1.5 $\mathrm{kW}$ electric motor through belt and pulley.

The effect of screw rotational speed on the screw conveyors performance characteristics were evaluated by selecting five rotational speeds of $200,300,400,500$ and $600 \mathrm{rpm}$. The desired rotational speeds of screw conveyors were adjusted using a speed inverter (LG model IC5, Korea) which was contacted to the drive electric motor, and then the rotational speed of screw conveyors was measured using a digital photo/contact tachometer (Lutron model DT-2236, Taiwan) on the conveyors shaft.

At each experiment, the paddy grains were poured from a big gravity flow charge hopper to the conveyor intake section and allowed the conveyor to operate at selected condition for a few minutes. This was defined as the conveyor run-in time. During experiments, adequate flow from the big gravity flow charge hopper was maintained to the intake section to assure that the intake section of the conveyors was totally submerged.

The screw conveyors capacity was determined through measuring the weight of conveyed grains over a known time. A weigh scale with an accuracy of $0.01 \mathrm{~g}$ (FLINTEC model PTS10000, Sweden) was used for this purpose. The actual volumetric capacity was expressed in bushels (one bushel $=1.244$ cubic feet) per hour (ASABE, 2006). In reality the actual capacity of a screw conveyor is considerably less than the theoretical capacity. This results in loss of volumetric efficiency. The volumetric efficiency $\left(\eta_{\mathrm{v}}\right)$ is defined as (Srivastava et al., 2006):

$$
\eta_{v}=\frac{Q_{a}}{Q_{t}}
$$

where: $\mathrm{Q}_{\mathrm{a}}$ is the actual volumetric capacity $\left(\mathrm{m}^{3} \mathrm{~min}^{-1}\right)$ and $\mathrm{Q}_{\mathrm{t}}$ is theoretical volumetric capacity $\left(\mathrm{m}^{3} \mathrm{~min}^{-1}\right)$ that can be expressed by the following (Srivastava et al., 2006):

$$
Q_{t}=\frac{\pi}{4}\left(d_{s f}^{2}-d_{s s}^{2}\right) l_{p} n
$$

where: $d_{s f}$ is screw flight diameter $(m), d_{s s}$ is screw shaft diameter $(m), l_{p}$ is the pitch length $(m)$ and $n$ is the screw rotational speed (rpm).

In order to express the screw conveyors throughput capacity in terms of the volumetric capacity, the values of $\mathrm{Q}_{\mathrm{a}}$ and $Q_{t}$ should be multiplied at the conveying grains bulk density (Srivastava et al., 2006). The bulk density of the paddy variety used in the current research at the moisture content of $11 \%$ was obtained $390 \mathrm{~kg} \mathrm{~m}^{-3}$ (Zareiforoush et al., 2009).

Since the conveyors were driven by means of an electric motor, their power requirements were measured by means of a power meter with the capability of monitoring (Roohi, 2003; Roohi et al., 2005). The instantaneous values of power data was continuously monitored on a computer every second. At each experiment, power data was recorded with the computer using a software program and the recorded data was stored on a spreadsheet for later statistical analysis and regression determination.

\subsection{Experimental design and statistical analysis}

The experiments were conducted to a factorial statistical design. Considering combination of the evaluated factors, 40 treatments were evaluated in the form of completely randomized block design. At each treatment, the experiments were replicated four times and then the mean values were reported. The experimental data were analyzed using analysis of variance (ANOVA) and the means were separated at the 5\% probability level applying Duncan's multiple range tests in SPSS 16 software program and analysis of regressions was performed using Microsoft Excel 2007 software.

\section{Results and discussion}

As seen in Table 1, variance analysis of the data indicated that the effects of auger diameter, screw clearance, and screw rotational speed on the volumetric capacity, volumetric efficiency and power requirement were all significant at the $1 \%$ level of probability. Interaction effect of auger diameter $\times$ screw speed was significant on the conveyors power requirements and volumetric efficiency at $1 \%$ probability level and interaction effect of auger diameter $\times$ screw clearance on the volumetric efficiency was significant at the $1 \%$ level of probability; while none 
of the interaction effects of screw clearance $\times$ screw speed, auger diameter $\times$ screw clearance, and screw speed $\times$ auger diameter $\times$ screw clearance on the power requirements and throughput capacity were significant $(P>0.05)$.

In the following paragraphs, the effects of each factor on the screw conveyors throughput and power requirements are comprehensively discussed.

\subsection{Volumetric capacity and volumetric efficiency}

The mean values of volumetric capacity and volumetric efficiency for the two evaluated screw conveyors at different screw clearances and rotational speeds are given in Table 2. As it can be seen, the volumetric capacity of the screw conveyor increased with increasing the auger diameter. This can be attributed to the greater space provided for conveying the grains with an increase in auger diameter. The volumetric capacity of the two evaluated screw conveyors with regard to screw clearance and screw rotational speed is illustrated in Fig. 2. As shown, for the evaluated screw conveyors, with increasing the screw rotational speed, the volumetric capacity increases and reaches to a maximum point and after this point, the volumetric capacity starts to decrease. Srivastava et al. (2006) has suggested that there may be two factors responsible for this behavior: (1) the restriction as grain flows into the intake of the conveyor, and (2) the centrifugal force due to the rotation of the grain mass at higher speeds. Konig and Riemann (1990) examined the influence of inlet screw diameter on screw conveyor capacity and reported a nearly linear increase in capacity with increasing inlet screw diameter up to a maximum point. After reaching to the point, capacity decreased. Bloome et al. (1996) reported that the conveying capacity for a $3 \mathrm{~m}$ long screw conveyor with a screw diameter of $15 \mathrm{~cm}$ and intake length of $30 \mathrm{~cm}$ in handling corn at $14.5 \%$ moisture increased from 850 to $1160 \mathrm{bu} \mathrm{h}^{-1}$, as the rotational speed of the conveyor increased from 400 to $600 \mathrm{rpm}$. Chang and Steele (1997) evaluated the performance characteristic of the inlet section of a $15.2 \mathrm{~cm}(6 \mathrm{in})$ screw conveyor. They reported that the conveying capacity of the inlet section of a screw conveyor increased from 32.1 to 42.8 and 24.9 to $34 \mathrm{t} \mathrm{h}^{-1}$, respectively, for two corn lots evaluated, as the rotational speed of conveyor increased from 413 to $690 \mathrm{rpm}$.

The results also revealed that for both the evaluated screw conveyors, increasing the screw clearance caused the volumetric capacity of the conveyors to be decreased (Fig. 2). This may be due to a decrease in the active layer (the layer which is conveyed by auger rotation) of the conveying grains as a result of increasing the distance between the screw rotating flight and conveyor housing. As it can be seen from Fig. 2, the maximum capacity of the conveyors occurred between the rotational speeds of 400 and $500 \mathrm{rpm}$. This range of the conveyors speed for maximum capacity was independent of the auger diameter and screw clearance. Nicolai et al. (2004) reported that the maximum capacity for 20 and $25 \mathrm{~cm}$ screw augers at all of the conditions evaluated in handling corn occurred between 784 and $853 \mathrm{rpm}$. Comparing these findings with the results obtained in the current study for the corresponding augers, it can be concluded that the volumetric capacity of screw conveyors and also the rotational speed gives the highest capacity for the conveyors can be affected by the properties of materials being conveyed. Since the bulk density of paddy grains is lower than that of corn, the real mass of the materials entered into the space between the screw flights at each revolution of the auger, that is to say the degree of fill, in the case of paddy grains is lower than that of corn. This can be also expounded by the effects of materials vortex motion resulting from higher centrifugal forces at higher rotations of the screw flights. Vortex motion arises as a result of internal friction, friction between the granular material and surface of the helical blade, and the infinitely variable helix angle of the helical flight from the outer periphery of the blade to the shaft. The vortex motion, together with the degree of fill, govern the volumetric efficiency and, hence, the volumetric throughput (Roberts, 1999).

Considering the results presented in Fig. 3, it becomes evident that as the rotational speed of augers increased, the volumetric efficiency of screw conveyors decreased. It seems that if the screw rotational speed is increased sufficiently, the centrifugal force may become so restrictive as to cause the volumetric efficiency to be declined. It can also be seen from Fig. 3 that with increasing the screw clearance, the volumetric efficiency decreases. Brusewitz and Persson (1969) reported that the screw clearance can affect the volumetric efficiency. They indicated that the diametric clearances up to $5-7 \%$ have little effect on the volumetric efficiency, but a drop in efficiency of $0.7 \%$ per $1 \%$ increase in clearance can be expected.

As shown in Table 2, the corresponding mean values of the screw conveyors volumetric efficiency at the different evaluated screw clearances and rotational speeds were obtained approximately near together. The volumetric efficiency of the 20 and $25 \mathrm{~cm}$ augers was lower than that of corresponding augers investigated by Nicolai et al., (2004). This result can also be used to explain how the different properties of materials being conveyed can affect the screw augers performance. The equations representing relationship between the 
volumetric efficiency of the evaluated screw conveyors with respect to the screw rotational speed at different screw clearances with their coefficient of determination $\left(\mathrm{R}^{2}\right)$ are presented in Table 3.

\subsection{Power requirement}

The mean values of power requirements for the two evaluated screw conveyors at different screw clearances and rotational speeds are given in Table 4. As shown, the power requirements of the screw conveyor increased with increasing the auger diameter. The power requirement increase because the volume of the material conveyed with augers having larger diameters is higher. The higher conveyed material volume, the higher power requirement. It can also be seen from Table 4 that for both the conveyors investigated the power requirements increased with increasing the screw rotational speed. This can be due to the fact that with increasing the screw rotational speed, the power needed for auger rotation increases. Moreover, the volume of the materials being conveyed at higher levels of screw rotational speeds is higher. The results confirms Srivastava et al. (2006) conclusion that the power requirements of an auger increases with increasing the auger rotational speed. Chang and Steele (1997) reported that with increasing the screw rotational speed from 413 to $690 \mathrm{rpm}$, the average power requirements for the inlet section of a $15.2 \mathrm{~cm}$ conveyor increased from 189 to $338 \mathrm{~W}$ and 209 to $350 \mathrm{~W}$, respectively, for two corn lots evaluated. They concluded that the power requirements for the inlet section tested were about 28 to $33 \%$ of the total power requirements for the $3 \mathrm{~m}(10 \mathrm{ft})$ long $15.2 \mathrm{~cm}$ (6 in.) diameter screw conveyor reported by White et al. (1962). Nicolai et al. (2004) determined the power requirements of large portable augers operating in a speed range of 250 to $1100 \mathrm{rpm}$ at inclination angles of 13, 20, and 30 degrees. They reported that for every $100 \mathrm{rpm}$ increase in screw speed for a $25 \mathrm{~cm}$ conveyor an increased power of $0.8 \mathrm{~kW}$ was needed for inclination angles greater than $20^{\circ}$. The power requirement was reduced to $0.5 \mathrm{~kW}$ for each $100 \mathrm{rpm}$ increase at the transport position of $13^{\circ}$ inclination.

The results also revealed that the power requirements of the screw conveyors decreased with increasing the screw clearance (Table 4). This may be due to a decrease in the mass of the grains being conveyed at higher screw clearances. This can be possibly attributed to a decrease in the value of frictional forces between the conveying grains and the conveyor housing wall at higher levels of screw clearances. Nicolai et al., (2006) reported that the power requirements for large portable bottom-drive swing augers were over twice the requirements of a top drive. They also indicated that each auger required an additional $2.89 \mathrm{~kW}$ power when the inclination angle was increased from transport position (13 deg.) to 20 degree.

The equations representing relationship between the power requirements of screw conveyors with respect to the screw rotational speed for the two conveyors evaluated at different screw clearances with their coefficient of determination $\left(\mathrm{R}^{2}\right)$ are presented in Table 5 .

\section{Conclusions}

(1) The power requirements of the screw conveyors increased with increasing the auger dimensions and screw rotational speed; whilst the value decreased with increasing the screw clearance.

(2) For both the tested screw conveyors, increasing the screw rotational speed increased the capacity up to a maximum value and further increases in speed caused a decrease in capacity.

(3) The screw speed for the maximum capacity of the conveyors was in the speed range of 400 to $500 \mathrm{rpm}$. This range of the conveyors speed for maximum capacity was independent of the auger dimension and also the screw clearance.

(4) As the screw clearance and screw rotational speed increased, the volumetric efficiency decreased significantly.

\section{Acknowledgments}

The authors would like to thank the Rice Research Institute of Iran (RRII) and University of Urmia for providing the laboratory facilities and financial support for this project. The authors are also grateful to Hamed Tavakoli and Kaveh Mollazade for their cooperation on this work.

\section{References}

Alizadeh, M. R., Minaei, S., Tavakoli, T., \& Khoshtaghaza, M. H. (2006). Effect of de-awning on physical properties of paddy, Pakistan Journal of Biological Science, 9, 1726-1731.

ASABE Standards. (2006). Terminology and specification definitions for agricultural auger conveying equipment, ASAE S374 MAR1975.

Asghari, A., Alimardani, R., Akram, A., \& Karparvar, H. (2008). Effect of auger speed and air Flow on discharge rate of bagasse. American-Eurasian Journal of Agricultural \& Environmental Science, 3(5), 743-747. 
Athanasiov, A., Gupta, M. L., \& Fragar, L. J. (2006). An insight into the grain auger injury problem in Queensland, Australia. Journal of Agricultural Safety \& Health, 12(1): 29-42.

Bloome, P., Harp, S., \& Brusewitz, G. (1996). Auger conveyors. OSU Extension Facts No. 1105. Stillwater, Okla.: Cooperative Extension Service, Oklahoma State Univ.

Brusewitz, A., \& Persson, S. (1969). Performance evaluation of screw augers. Copyright American Society of Agricultural and Biological Engineers. Michigan, USA.

Burr, M. S., Kocher, M. F., \& Jones, D. D. (1998). Design of tapered augers for uniform unloading particulate materials from rectangular cross-section containers. Transactions of the ASAE, 41(5), 1415-1421.

Chang, C. S., \& Steele, J. L. (1997). Performance characteristics of the inlet section of a screw auger. Applied Engineering in Agriculture, 13(5), 627-630.

Dai, J., \& Grace, J. R. (2008). A model for biomass screw feeding. Powder Techn, 186, 40-55.

Konig, A., \& Riemann, U. (1990). Investigation on vertical auger conveyors. NIAE Translation 90. Landtechnische Forschung, 10(2), 45-51.

Maleki, M. R., Jafari, J. F., Raufat, M. H., Mouazen, A. M., \& Baerdemaeker, J. D. (2006). Distribution uniformity of a multi-flight auger as a grain drill metering device. Biosystems Engineering, 94(4), 535-543.

Moysey, P. A., \& Thompson, M. R. (2005). Modelling the solids inflow and solids conveying of single-screw extruders using the discrete element method. Powder Technology, 153, 95 - 107.

Nicolai, R., Ollerich, J., \& Kelley, J. (2004). Screw auger power and throughput analysis. ASAE/CSAE Annual International Meeting. Ottawa, Ontario, Canada. Paper Number: 046134.

Nicolai, R., Dittbenner, A., \& Pasikanti, S. (2006). Large portable auger throughput analysis. ASABE Annual International Meeting. Portland, Oregon. Paper Number: 066043.

Pan, Z., Khir, R., Godfrey, L. D., Lewis, R., Thompson, J. F., \& Salim, A. (2008). Feasibility of simultaneous rough rice drying and disinfestations by infrared radiation heating and rice milling quality. Journal of Food Engineering, 84, 469-479.

Roberts, A. W. (1999). The influence of granular vortex motion on the volumetric performance of enclosed screw conveyors. Powder Technology, 104, 56-67.

Roohi, G. R. (2003). Study of energy consumption in the hulling and whitening of three paddy varieties in Guilan, Iran. Master of Science Thesis, Tehran University, Tehran, Iran.

Roohi, G. R., Minaei, S., \& Payman, H. (2005). Designing, manufacturing and evaluation of a power meter with the capability of data monitoring. Third National Conference of Agricultural Machinery Engineering and Mechanization in Iran, Kerman, Iran.

Srivastava, A. K., Goering, C. E., Rohrbach, R. P., \& Buckmaster, D. R. (2006). Engineering principles of agricultural machines, Second Edition, ASABE. Copyright American Society of Agricultural and Biological Engineers. Michigan, USA. pp: 491-524.

White, G. M., Schaper, L. A., Ross, I. J., \& Isaacs, G. W. (1962). Performance characteristics of enclosed screw conveyors handling shelled corn and soybeans. Research Bulletin No. 740. Lafayette. Ind.: Indiana Agric. Exp. Station, Purdue Univ.

Zareiforoush, H., Komarizadeh, M. H., \& Alizadeh, M. R. (2009). Effect of moisture content on some physical properties of paddy grains. Research Journal of Applied Science, Engineering and Technology, 1(3), $132-139$. 
Table 1. Analysis of the variance of the parameters considered on the power requirements and throughput capacity

\begin{tabular}{|l|c|c|c|c|}
\hline $\begin{array}{l}\text { Variation } \\
\text { source }\end{array}$ & DF & $\begin{array}{c}\text { Volumetric capacity, } \\
\text { bu h }^{-1}\end{array}$ & $\begin{array}{c}\text { Volumetric efficiency, } \\
\%\end{array}$ & $\begin{array}{c}\text { Power requirement, } \\
\text { W }\end{array}$ \\
\hline $\mathrm{AD}$ & 1 & $11571050.99^{\mathrm{a}}$ & $187.67^{\mathrm{a}}$ & $165167.79^{\mathrm{a}}$ \\
\hline $\mathrm{SS}$ & 4 & $264191.93^{\mathrm{a}}$ & $1929.85^{\mathrm{a}}$ & $934.85^{\mathrm{a}}$ \\
\hline $\mathrm{SC}$ & 3 & $63560.11^{\mathrm{a}}$ & $58.03^{\mathrm{a}}$ & $1833.94^{\mathrm{a}}$ \\
\hline $\mathrm{AD} \times \mathrm{SS}$ & 4 & $1656.86^{\mathrm{ns}}$ & $12.98^{\mathrm{a}}$ & $24.39^{\mathrm{ns}}$ \\
\hline $\mathrm{AD} \times \mathrm{SC}$ & 3 & $1399.26^{\mathrm{ns}}$ & $10.12^{\mathrm{a}}$ & $4.39^{\mathrm{ns}}$ \\
\hline $\mathrm{SS} \times \mathrm{SC}$ & 12 & $635.32^{\mathrm{ns}}$ & $0.91^{\mathrm{ns}}$ & $10.56^{\mathrm{ns}}$ \\
\hline $\mathrm{AD} \times \mathrm{SS} \times \mathrm{SC}$ & 12 & $330.77^{\mathrm{ns}}$ & $0.48^{\mathrm{ns}}$ & 4.61 \\
\hline Error & 120 & 8.47 & 6.55 & 137 \\
\hline
\end{tabular}

a Corresponding to confidence of interval, $99 \%$; ${ }^{b}$ Corresponding to confidence of interval, 95\%; ns: Corresponding to no significant difference; AD: Auger diameter; SS: Screw speed; SC: Screw clearance

Table 2. Mean values of volumetric capacity and volumetric efficiency for the evaluated screw conveyors at different screw clearances and screw rotational speeds

\begin{tabular}{|c|c|c|c|c|c|c|c|c|c|}
\hline \multirow{3}{*}{\begin{tabular}{|c} 
Auger \\
diameter, \\
cm \\
\end{tabular}} & \multirow{3}{*}{$\begin{array}{c}\text { Screw } \\
\text { speed, } \\
\text { rpm }\end{array}$} & \multicolumn{8}{|c|}{ Screw clearance, $\mathrm{mm}$} \\
\hline & & \multicolumn{2}{|c|}{6} & \multicolumn{2}{|c|}{9} & \multicolumn{2}{|r|}{12} & \multicolumn{2}{|r|}{15} \\
\hline & & $\mathrm{Q}_{\mathrm{a}}, \mathrm{bu} \mathrm{h}^{-1}$ & $\mathrm{E}_{\mathrm{v}}, \%$ & $\mathrm{Q}_{\mathrm{a}}, \mathrm{bu} \mathrm{h}^{-1}$ & $E_{v}, \%$ & $\mathrm{Q}_{\mathrm{a}}, \mathrm{bu} \mathrm{h}^{-1}$ & $E_{v}, \%$ & $\mathrm{Q}_{\mathrm{a}}, \mathrm{bu} \mathrm{h}^{-1}$ & $E_{v}, \%$ \\
\hline \multirow{5}{*}{20} & 200 & $\begin{array}{c}495.91 \\
(18.59)^{*}\end{array}$ & $\begin{array}{l}37.03 \\
(1.84)\end{array}$ & $\begin{array}{l}483.46 \\
(15.75)\end{array}$ & $\begin{array}{l}36.10 \\
(2.86)\end{array}$ & $\begin{array}{l}449.06 \\
(15.61)\end{array}$ & $\begin{array}{l}33.53 \\
(2.65)\end{array}$ & $\begin{array}{l}428.10 \\
(15.57)\end{array}$ & $\begin{array}{l}31.97 \\
(2.14)\end{array}$ \\
\hline & 300 & $\begin{array}{l}631.18 \\
(17.51)\end{array}$ & $\begin{array}{l}31.42 \\
(1.22)\end{array}$ & $\begin{array}{l}591.88 \\
(16.06)\end{array}$ & $\begin{array}{l}29.46 \\
(2.89)\end{array}$ & $\begin{array}{l}571.24 \\
(17.73)\end{array}$ & $\begin{array}{l}28.44 \\
(1.88)\end{array}$ & $\begin{array}{l}536.19 \\
(14.09)\end{array}$ & $\begin{array}{l}26.69 \\
(2.69)\end{array}$ \\
\hline & 400 & $\begin{array}{l}704.88 \\
(20.21)\end{array}$ & $\begin{array}{l}26.32 \\
(0.75)\end{array}$ & $\begin{array}{l}688.18 \\
(19.27)\end{array}$ & $\begin{array}{l}25.69 \\
(0.83)\end{array}$ & $\begin{array}{l}672.13 \\
(14.65)\end{array}$ & $\begin{array}{l}25.09 \\
(1.15)\end{array}$ & $\begin{array}{l}603.03 \\
(18.31)\end{array}$ & $\begin{array}{l}22.51 \\
(1.81)\end{array}$ \\
\hline & 500 & $\begin{array}{l}715.69 \\
(18.47)\end{array}$ & $\begin{array}{l}21.38 \\
(1.28)\end{array}$ & $\begin{array}{l}685.56 \\
(18.34)\end{array}$ & $\begin{array}{l}20.48 \\
(0.72)\end{array}$ & $\begin{array}{l}660.66 \\
(19.38)\end{array}$ & $\begin{array}{l}19.73 \\
(0.88)\end{array}$ & $\begin{array}{l}598.76 \\
(19.45)\end{array}$ & $\begin{array}{l}17.88 \\
(1.77)\end{array}$ \\
\hline & 600 & $\begin{array}{c}679.01 \\
(19.73) \\
\end{array}$ & $\begin{array}{l}16.90 \\
(1.08) \\
\end{array}$ & $\begin{array}{c}660.66 \\
(18.79) \\
\end{array}$ & $\begin{array}{l}16.44 \\
(0.71) \\
\end{array}$ & $\begin{array}{l}627.58 \\
(19.64) \\
\end{array}$ & $\begin{array}{l}15.62 \\
(0.96) \\
\end{array}$ & $\begin{array}{l}571.57 \\
(18.72) \\
\end{array}$ & $\begin{array}{c}14.23 \\
(0.54) \\
\end{array}$ \\
\hline \multirow{5}{*}{25} & 200 & $\begin{array}{c}1003.93 \\
(36.62)\end{array}$ & $\begin{array}{l}35.46 \\
(2.14)\end{array}$ & $\begin{array}{l}991.48 \\
(24.31)\end{array}$ & $\begin{array}{l}35.02 \\
(1.85)\end{array}$ & $\begin{array}{l}967.25 \\
(14.64)\end{array}$ & $\begin{array}{l}34.16 \\
(1.52)\end{array}$ & $\begin{array}{l}943.66 \\
(17.32)\end{array}$ & $\begin{array}{l}33.33 \\
(0.61)\end{array}$ \\
\hline & 300 & $\begin{array}{c}1166.39 \\
(38.87)\end{array}$ & $\begin{array}{l}27.46 \\
(2.44)\end{array}$ & $\begin{array}{c}1145.11 \\
(25.36)\end{array}$ & $\begin{array}{l}26.96 \\
(1.59)\end{array}$ & $\begin{array}{c}1112.13 \\
(36.23)\end{array}$ & $\begin{array}{l}26.19 \\
(0.85)\end{array}$ & $\begin{array}{c}1095.32 \\
(30.38)\end{array}$ & $\begin{array}{l}25.79 \\
(1.18)\end{array}$ \\
\hline & 400 & $\begin{array}{c}1262.69 \\
(36.92)\end{array}$ & $\begin{array}{l}22.30 \\
(1.65)\end{array}$ & $\begin{array}{c}1210.61 \\
(25.29)\end{array}$ & $\begin{array}{l}21.38 \\
(1.44)\end{array}$ & $\begin{array}{l}1186.71 \\
(31.11)\end{array}$ & $\begin{array}{l}20.96 \\
(1.08)\end{array}$ & $\begin{array}{c}1170.33 \\
(34.93)\end{array}$ & $\begin{array}{l}20.67 \\
(0.62)\end{array}$ \\
\hline & 500 & $\begin{array}{c}1274.92 \\
(31.71)\end{array}$ & $\begin{array}{l}18.01 \\
(1.45)\end{array}$ & $\begin{array}{c}1219.78 \\
(26.27)\end{array}$ & $\begin{array}{l}17.23 \\
(1.37)\end{array}$ & $\begin{array}{l}1188.99 \\
(35.66)\end{array}$ & $\begin{array}{l}16.80 \\
(0.64)\end{array}$ & $\begin{array}{l}1155.91 \\
(36.68)\end{array}$ & $\begin{array}{l}16.33 \\
(0.54)\end{array}$ \\
\hline & 600 & $\begin{array}{c}1237.80 \\
(36.82)\end{array}$ & $\begin{array}{l}14.57 \\
(0.78)\end{array}$ & $\begin{array}{c}1185.72 \\
(24.21)\end{array}$ & $\begin{array}{l}13.96 \\
(0.68)\end{array}$ & $\begin{array}{l}1162.47 \\
(25.51)\end{array}$ & $\begin{array}{l}13.69 \\
(0.45)\end{array}$ & $\begin{array}{c}1130.36 \\
(34.76)\end{array}$ & $\begin{array}{l}13.31 \\
(0.41)\end{array}$ \\
\hline
\end{tabular}

*Figures in parentheses are standard deviation. $Q_{a}$ : actual volumetric capacity, and $E_{v}$ : volumetric efficiency 
Table 3. Equations representing relationship between the volumetric efficiency and screw rotational speed at different screw clearances and conveyor dimensions

\begin{tabular}{|c|c|c|c|c|}
\hline Auger diameter, cm & \multicolumn{2}{|c|}{20} & 25 \\
\hline Screw clearance, $m m$ & Relationship & $\mathrm{R}^{2}$ & Relationship & $\mathrm{R}^{2}$ \\
\hline 6 & $\mathrm{E}_{\mathrm{v}}=-503 \mathrm{E}-4 \mathrm{~S}_{\mathrm{S}}+46.73$ & 0.996 & $\mathrm{E}_{\mathrm{v}}=-512 \mathrm{E}-4 \mathrm{~S}_{\mathrm{S}}+44.06$ & 0.972 \\
\hline 9 & $\mathrm{E}_{\mathrm{v}}=-483 \mathrm{E}-4 \mathrm{~S}_{\mathrm{S}}+44.96$ & 0.992 & $\mathrm{E}_{\mathrm{v}}=-519 \mathrm{E}-4 \mathrm{~S}_{\mathrm{S}}+43.65$ & 0.968 \\
\hline 12 & $\mathrm{E}_{\mathrm{v}}=-445 \mathrm{E}-4 \mathrm{~S}_{\mathrm{S}}+42.29$ & 0.996 & $\mathrm{E}_{\mathrm{v}}=-503 \mathrm{E}-4 \mathrm{~S}_{\mathrm{S}}+42.50$ & 0.967 \\
\hline 15 & $\mathrm{E}_{\mathrm{v}}=-443 \mathrm{E}-4 \mathrm{~S}_{\mathrm{S}}+40.37$ & 0.995 & $\mathrm{E}_{\mathrm{v}}=-495 \mathrm{E}-4 \mathrm{~S}_{\mathrm{S}}+41.68$ & 0.972 \\
\hline
\end{tabular}

$E_{v}:$ volumetric efficiency, and $S_{S}:$ Screw rotational speed

Table 4. Mean values of power requirements for the evaluated screw conveyors at different screw clearances and screw rotational speeds

\begin{tabular}{|c|c|c|c|c|c|}
\hline \multirow{3}{*}{$\begin{array}{c}\text { Auger } \\
\text { diameter, } \\
\mathrm{cm}\end{array}$} & \multirow{3}{*}{$\begin{array}{c}\text { Screw } \\
\text { speed, } \\
\text { rpm }\end{array}$} & \multicolumn{4}{|c|}{ Power requirements, $\mathrm{W}$} \\
\hline & & \multicolumn{4}{|c|}{ Screw clearance, $\mathrm{mm}$} \\
\hline & & 6 & 9 & 12 & 15 \\
\hline \multirow{5}{*}{20} & 200 & $130.47(4.55)^{*}$ & $128.58(8.09)$ & $124.86(7.71)$ & $121.13(8.36)$ \\
\hline & 300 & $196.25(5.02)$ & $192.18(6.58)$ & $190.73(8.19)$ & $186.69(8.18)$ \\
\hline & 400 & $263.17(4.05)$ & $261.82(6.06)$ & $259.66(7.33)$ & $255.74(4.01)$ \\
\hline & 500 & $327.49(8.58)$ & $324.77(8.62)$ & $321.82(4.58)$ & $317.41(9.63)$ \\
\hline & 600 & $373.36(9.17)$ & $369.14(4.41)$ & $365.78(4.80)$ & $361.59(6.57)$ \\
\hline \multirow{5}{*}{25} & 200 & $186.47(5.27)$ & $184.93(4.82)$ & $182.72(5.33)$ & $178.26(4.55)$ \\
\hline & 300 & $264.19(7.81)$ & $260.44(6.21)$ & $255.38(6.52)$ & $247.83(7.59)$ \\
\hline & 400 & $317.52(6.56)$ & $314.49(6.81)$ & $308.65(4.81)$ & $300.25(5.09)$ \\
\hline & 500 & $387.58(4.81)$ & $384.26(3.56)$ & $381.66(6.91)$ & $375.36(4.83)$ \\
\hline & 600 & $461.49(5.46)$ & $458.64(5.23)$ & $456.93(8.66)$ & $450.77(7.01)$ \\
\hline
\end{tabular}

*Values in parentheses are standard deviation

Table 5. Equations representing relationship between the screw conveyors power requirements and screw rotational speed at different screw clearances and auger dimensions

\begin{tabular}{|c|c|c|c|c|}
\hline Auger diameter, cm & \multicolumn{2}{|c|}{20} & \multicolumn{2}{c|}{25} \\
\hline Screw clearance, $m m$ & Relationship & $\mathrm{R}^{2}$ & Relationship & $\mathrm{R}^{2}$ \\
\hline 6 & $\mathrm{P}_{\mathrm{s}}=617 \mathrm{E}-3 \mathrm{~S}_{\mathrm{S}}+11.34$ & 0.995 & $\mathrm{P}_{\mathrm{s}}=673 \mathrm{E}-3 \mathrm{~S}_{\mathrm{S}}+54.08$ & 0.997 \\
\hline 9 & $\mathrm{P}_{\mathrm{s}}=614 \mathrm{E}-3 \mathrm{~S}_{\mathrm{S}}+9.81$ & 0.994 & $\mathrm{P}_{\mathrm{s}}=671 \mathrm{E}-3 \mathrm{~S}_{\mathrm{S}}+52.05$ & 0.996 \\
\hline 12 & $\mathrm{P}_{\mathrm{s}}=613 \mathrm{E}-3 \mathrm{~S}_{\mathrm{S}}+7.39$ & 0.994 & $\mathrm{P}_{\mathrm{s}}=675 \mathrm{E}-3 \mathrm{~S}_{\mathrm{S}}+47.19$ & 0.997 \\
\hline 15 & $\mathrm{P}_{\mathrm{s}}=611 \mathrm{E}-3 \mathrm{~S}_{\mathrm{S}}+3.85$ & 0.996 & $\mathrm{P}_{\mathrm{s}}=672 \mathrm{E}-3 \mathrm{~S}_{\mathrm{S}}+41.47$ & 0.995 \\
\hline
\end{tabular}

$P_{s}$ : Power requirement, and $S_{S}$ : Screw rotational speed 


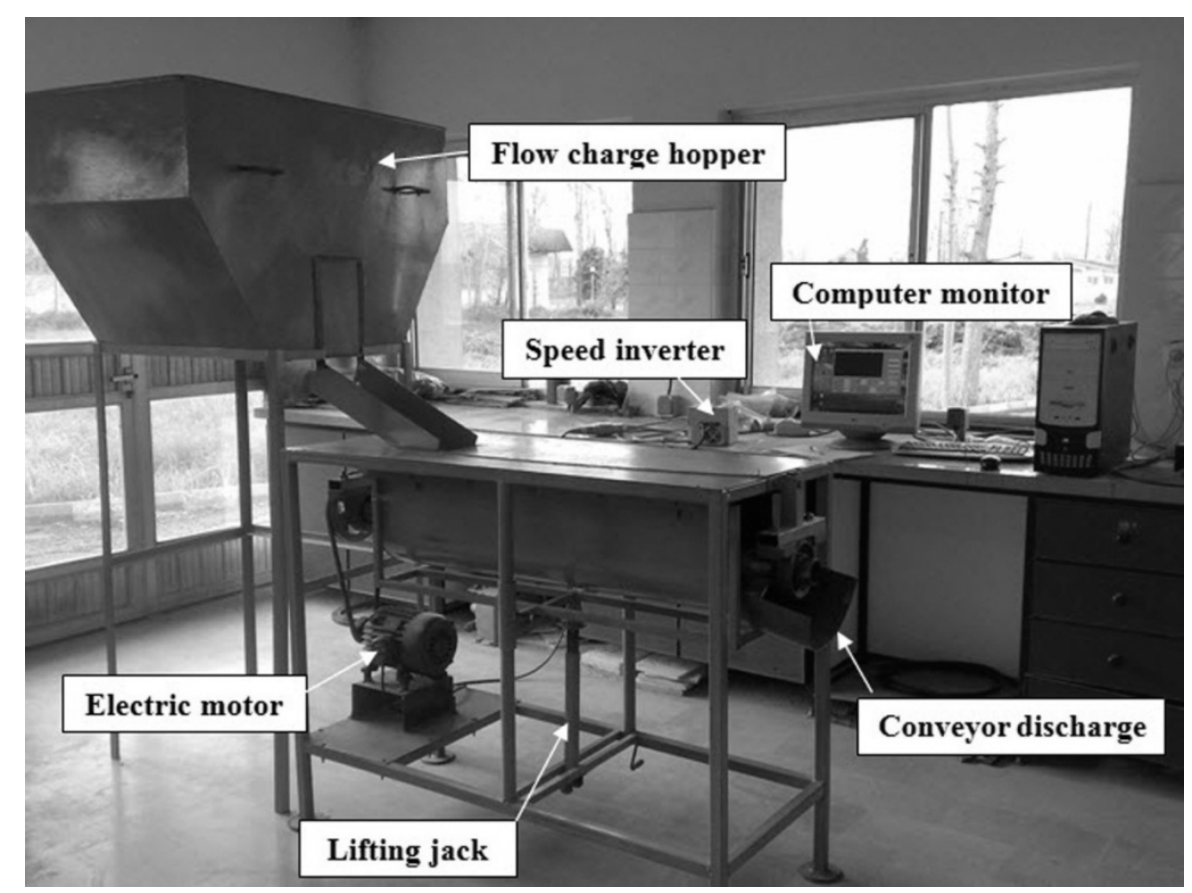

Figure 1. Screw conveyor test set up 


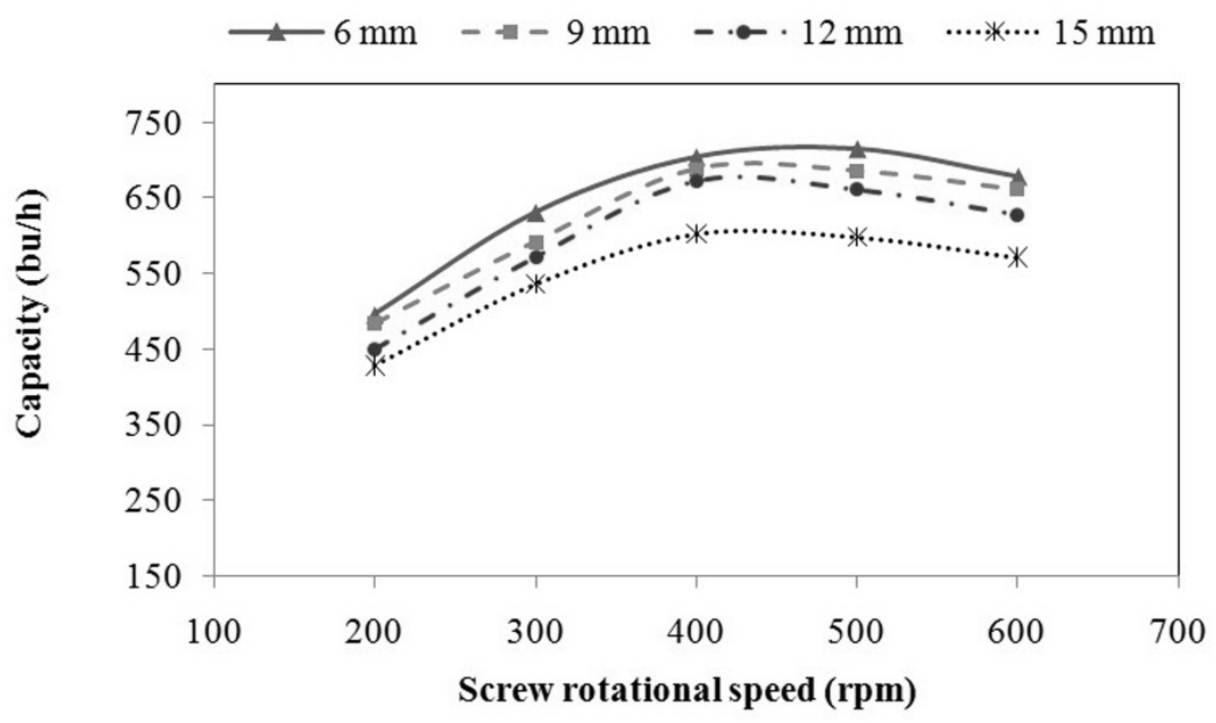

(a)

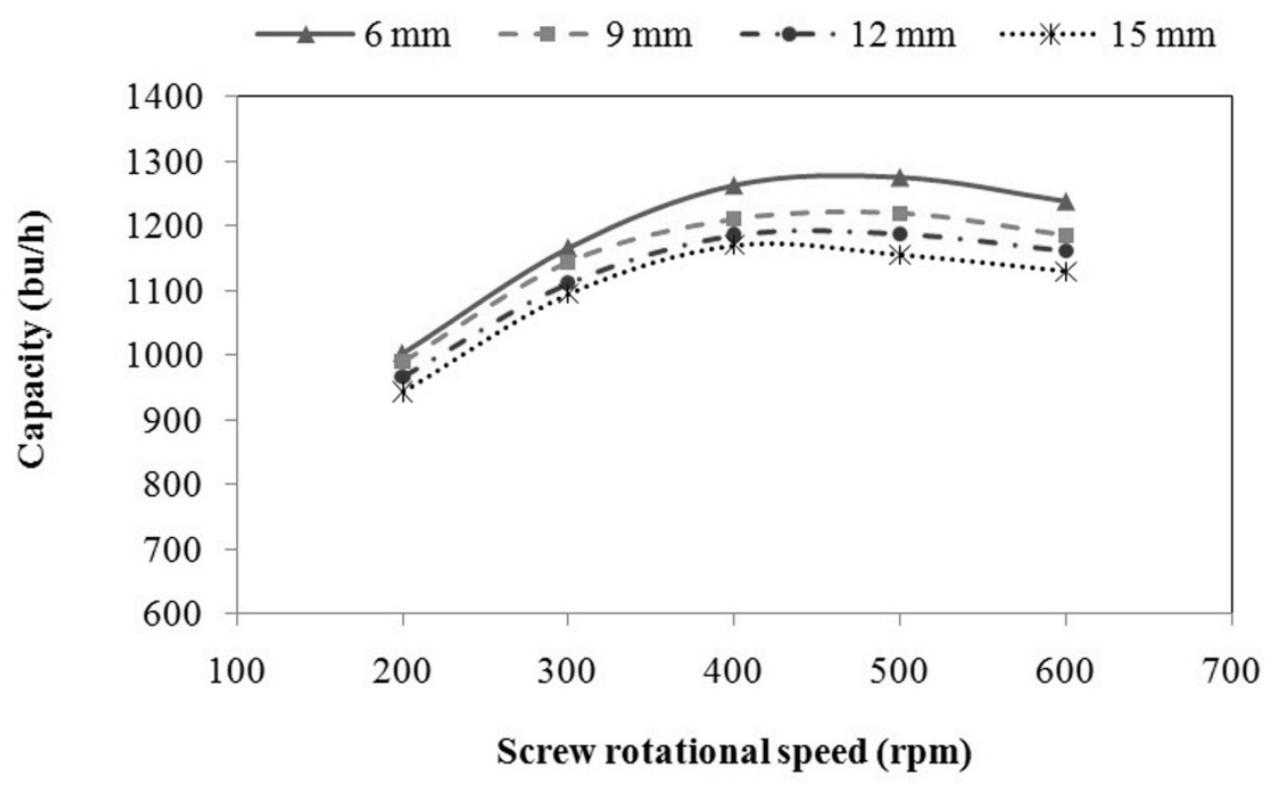

(b)

Figure 2. Volumetric capacity for: (a) $20 \mathrm{~cm}$ and (b) $20 \mathrm{~cm}$ screw conveyors with respect to screw rotational speed and screw clearance; $\boldsymbol{\Delta} 6 \mathrm{~mm},-9 \mathrm{~mm}, \bullet 12 \mathrm{~mm}$ and $\times 15 \mathrm{~mm}$ screw clearance 


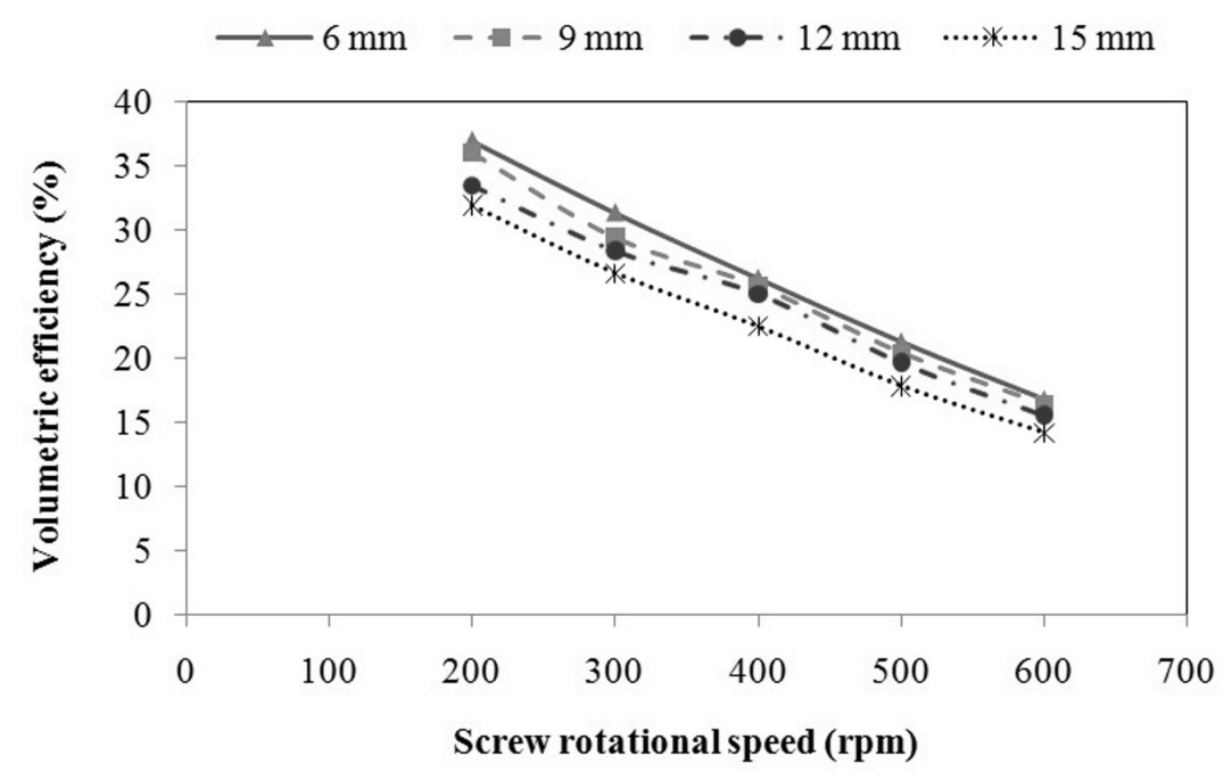

(a)

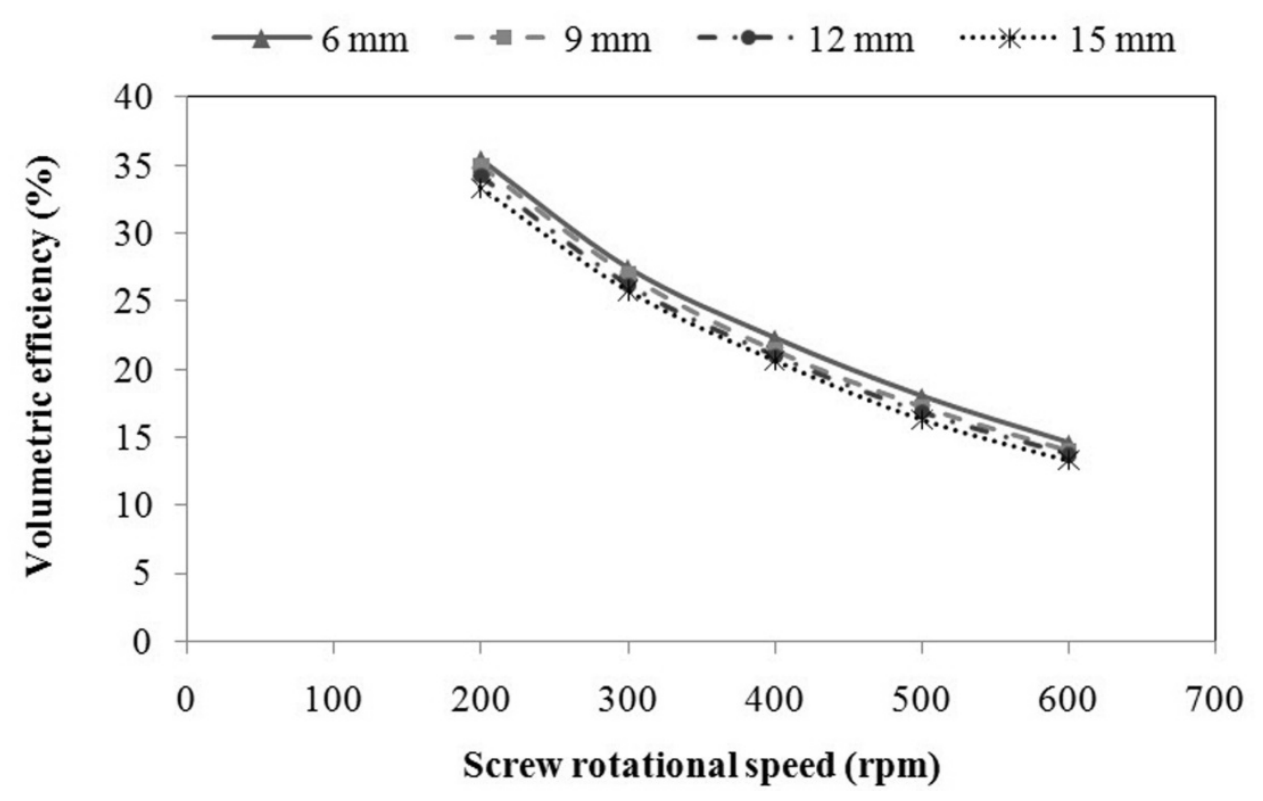

(b)

Figure 3. Volumetric efficiency for: (a) $20 \mathrm{~cm}$ and (b) $20 \mathrm{~cm}$ screw conveyors with respect to screw rotational speed and screw clearance; $\Delta 6 \mathrm{~mm}, \mathbf{m m}, \bullet 12 \mathrm{~mm}$ and $\times 15 \mathrm{~mm}$ screw clearance 